\title{
The effect of residual stress on the electrochemical corrosion behavior of Fe-based amorphous coatings in chloride-containing solutions
}

Y. Wang ${ }^{\text {a,b,c }}, \quad$ K.Y. Li ${ }^{\mathrm{b}}, \quad$ F. Scenini ${ }^{\mathrm{c}}, \quad$ J.Jiao ${ }^{\mathrm{a}}, \quad$ S.J.Qu ${ }^{\mathrm{a}}, \quad$ Q.Luo ${ }^{\mathrm{a}}$, J. Shen ${ }^{\mathrm{a}, *}$

${ }^{a}$ School of Materials Science and Engineering, Tongji University, 4800 Caoan Road, Shanghai 201084, P.R. China

${ }^{b}$ School of Mechanical Science and Engineering, Northeast Petroleum University, 199 Fazhan Road, Daqing 163318, P.R. China

${ }^{c}$ Materials Performance Centre, The University of Manchester, Oxford Road, Manchester M13 9PL, United Kingdom

*Corresponding author.

Tel.: +862169581009 .

E-mail: junshen@tongji.edu.cn (J.Shen) 


\begin{abstract}
The electrochemical corrosion and passive behavior of activated combustion high-velocity air fuel FeCrMoMnWBCSi amorphous metallic coatings (AMCs) under different geometries that produced a variable tensile residual stresses were investigated in chloride-containing solutions by using electrochemical measurements and X-ray photoelectron spectroscopy. The tensile residual stresses of AMCs were determined by the mechanical method of sharp indentation testing. A systematic detrimental effect of tensile residual stress on passive current density and localized corrosion was found. The detrimental effect of residual stress was aggravated at higher temperatures and acidity. The implication of high donor density on the passive film stability, derived from Mott-Schottky analysis, is also discussed
\end{abstract}

Keywords: metal coatings; polarization; XPS; amorphous structures; residual stress; passivity 


\section{Introduction}

Fe-based amorphous metallic coatings (AMCs) have been developed to combine high mechanical performance and corrosion resistance [1-2] and are promising materials with enhanced hardness to be used in harsh abrasive and/or corrosive conditions [3-8]. These coatings are generally deposited by thermal spray techniques, such as high-velocity axial plasma [2], high-velocity oxygen fuel (HVOF) [6-7] and high-velocity air fuel (HVAF) [8] spraying methods. The most important effect that occurs during thermal spraying is the generation of internal residual stresses which are localized and can affect the durability of coatings. Since the coating process involves a rapid thermal cycle, particle impingement and local deformation, residual stresses can be generated in the coating. Specifically, the peening effect would introduce compressive stresses whilst the thermal mismatch would promote tensile stresses. The overall stress status in the coating depends on the specific contribution of each phenomena [9] and strongly depends on the coating parameters and geometry of the sample.. The nature and magnitude of internal stresses plays an important role. For example, compressive stresses tend to close microcracks that are directly perpendicular to the coating surface. Conversely, tensile residual stresses may lead to high susceptibility to debonding and cracking, which can eventually result in a complete detachment of coating [10]. Therefore, understanding residual tensile stress that may lead to coating is critical; however it is also very important to understand the additional role of environmental interactions which can have a synergistic effect and promote premature coating failure. The effects of stress on local corrosion sensitivity have been investigated extensively in the past decades, but the effects of residual stress on localized corrosion, even for pitting corrosion, are still unclear.

Many studies have been carried out to measure the residual stresses that is generated 
after the thermal spraying coating process, mainly on plasma-sprayed ceramic NiCrAlY and YSZ coatings which experience tensile stresses mainly due to quench and thermal mismatch [9,11]. By contrast, in coatings obtained via HVOF, peening stress is typically dominant because of higher spray particle velocity and lower temperature, and the residual stress can either be exhibit compressive [9] or tensile [12]. The process parameters during deposition may also influence the coating behavior [9] and therefore the knowledge of residual stress profiles allows the optimization of the spraying techniques. Several different techniques have been developed and applied to measure the residual stress of metallic coatings; these include X-ray diffraction (XRD) [13], neutron diffraction [14], layer-by-layer removal [15],hole drilling [16] and in-situ curvature-monitoring technique [17]. However, to date, only a few studies have been conducted to evaluate residual stress on amorphous materials, particularly for AMCs.

Most recently, a variant of the thermal spraying HVAF technique has been developed into the activated combustion HVAF (AC-HVAF) technique. This relatively new method can deliver higher spraying rate and deposition efficiency compared to conventional hypersonic flame spraying technology $[8,18]$. In the AC-HVAF process, spray particles are accelerated to velocities of $700 \mathrm{~m} \cdot \mathrm{s}^{-1}-850 \mathrm{~m} \cdot \mathrm{s}^{-1}$, resulting in high-impact coatings with extremely low oxide content, which may yield coatings with low porosity and high bonding strength [19]. However, to date, a detailed evaluation of the effects of residual stresses on the structure and corrosion performance of AC-HVAF AMCs does not exist. Therefore, understanding the implication of residual stress on AMCs in chloride-containing solutions is important and should be conducted.

The aim of this paper is to characterize the effect of geometry on the evolution of 
residual stresses and understand its implication on the electrochemical behavior of AMCs FeCrMnMoWBCSi deposited via AC-HVAF when immersed in chloride-containing solutions. The electrochemical behavior was investigated through potentiodynamic polarization, cyclic polarization behavior, current-time transient, Mott-Schottky (M-S) and electrochemical impedance spectroscopy (EIS) analyses. X-ray photoelectron spectroscopy (XPS) was also used to investigate the nature and composition of the passive. Finally, the process by which residual stress influences uniform corrosion and pitting corrosion is proposed and discussed.

\section{Material and methods}

\subsection{Materials}

The powder materials used in the HVAF coating was obtained from a base materials with the required composition (Fe54.2Cr18.3Mo13.7Mn2.0W6.0B3.3C1.1Si1.4, wt.\%) which was produced via induction melting. The master alloy was produced by induction-melting of high-purity elemental base constituents (Fe, Cr, W, C, Si: 99.9\%;, Mo: 98.5\%;Mn: 99.7\%; FeB: $99 \%$ (20.06 wt.\% boron)) in a copper crucible under inert atmosphere. Subsequently the powders were prepared by high pressure argon gas atomization using a close-coupled annulus nozzle with a melt delivery inner diameter of $3 \mathrm{~mm}$, at $1600 \mathrm{~K}$ and a dynamic pressure of 7 MPa. The atomized powders were then sieved, and only those with a particle size lower than $45 \mu \mathrm{m}$ were used for spraying onto the $316 \mathrm{~L}$ stainless steel substrate. Prior the spraying coating being applied, the surfaces of the substrate were smoothed by a grinding machine, degreased with acetone, cleaned with alcohol, and grit-blasted. An AK-07-03 Gun was employed for AcuKote-HVAF thermal spraying and the AC-HVAF spraying parameters are shown in Table 1 . The thickness of all the AMCs were about $150 \mu \mathrm{m}$. 
Different convex arcs of the 316L stainless steel (SS) substrate coated with the same spraying condition of the AC-HVAF AMCs were fabricated for the corrosion tests, as shown in Fig. 1. The rationale of using different convex arcs was to obtain coating which exhibits different tensile stresses. The residual stresses were measured on the coating via the sharp indentation testing methodology [10,20-22]. Measurements were conducted on a micro MVK-H3 Vickers hardness tester with the load of $30 \mathrm{~kg}$ for $10 \mathrm{~s}$ and the values of the hardness are reported in Table 2. This value of load was considered adequate to measure the stress in these relatively thin films $(\sim 150 \mu \mathrm{m})$. In fact, recalling that the Vickers hardness indentation pyramid has an angle of $136^{\circ}$, assuming a max diagonal of the measured print of $300 \mu \mathrm{m}(\mathrm{Hv}>618)$, the maximum depth of the print would be $61 \mu \mathrm{m}$, which is less than half of the total thickness of the coating. In order obtain reliable measurements, the indentation testing should be operated on the identical plane surfaces. However, two different convex arcs of the substrate were introduced into generating different residual stress of coatings in this research. Therefore, to minimize the effect of different surface arcs on indentation testing, the indentation was carried out at the apex of the curvature. For each samples five measurements were carried out to ensure reproducibility in the results. The residual stain $\varepsilon_{\text {res }}$ and residual stress $\sigma_{r e s}$ of coatings were calculated according to the following equations obtained from the literature [21-22]:

$$
\begin{gathered}
\varepsilon_{r e s}=\left(\frac{H v}{3.4 \sigma_{0}}\right)^{1 / n}-0.08 \\
\sigma_{r e s}=\sigma_{0}\left|\varepsilon_{r e s}\right|^{n} \times\left(e^{\frac{C^{2}-C_{0}^{2}}{0.32}}-1\right)
\end{gathered}
$$

Where $H v$ is the Vicker Hardness of the material; $\sigma_{0}$ is the strength coefficient of the material, as for Fe-based materials $\sigma_{0}=5 ; n$ is the inherent attribute of the material, the material is 
absolute elastic body when $n=1$ and that is no strain strengthening when $n=0$, the value of $n$ is 0.2 in this research for the inferior toughness of Fe-based AMCs. $C_{0}$ and $C$ are the area ratios of Vickers indentation to Cone indentation, $C_{0}$ is the stress-free sample and $C_{0}=1$. In equation (1) and (2), $H v$ and $C$ are the global indentation properties given by the experiments. The residual tensile stress values of AMCs were derived according to the shape of the indentation as showed in Fig.2.

\subsection{Characterization of the coatings}

X-Ray Diffraction (XRD) analyzes were carried out on the AMCs on a Rigaku D/max 2400 X-ray diffractometer. The thermal stability of AMC coating (which was mechanically removed from the substrate prior to analysis) and the ribbon were carried out on differential scanning calorimeter (DSC) (PerkinElmer DSC-7) with a constant heating rate of $20 \mathrm{~K} \cdot \mathrm{min}^{-1}$. The porosity of the AMCs was calculated as the average of five measurements obtained on an optical microscope (MEF-4) equipped with porosity analysis software. The microstructural features of the AMCs were observed using a JMS-6301 scanning electron microscope (SEM).

\subsection{Static electrochemical measurements}

Electrochemical behavior of AMCs was examined by a CorrTest CS350 electrochemical workstation. All measurements were carried out in a $1.5 \mathrm{~L}$ standard three-electrode glass cell. A platinum plate was uses as the counter electrode whilst a saturated calomel electrode (SCE) was the reference electrode. The SCE was connected to the cell via a Luggin probe. The tests were carried out in $0.50 \mathrm{M} \mathrm{NaCl}$ solution at different temperatures $\left(20^{\circ} \mathrm{C}, 50^{\circ} \mathrm{C}\right.$ and $\left.80{ }^{\circ} \mathrm{C}\right)$ and $\mathrm{pH}$ values $(0.50 \mathrm{M} \mathrm{NaCl} \mathrm{pH}=7.0,0.25 \mathrm{M} \mathrm{NaCl}+0.25 \mathrm{M} \mathrm{HCl} \mathrm{pH}=0.6,0.50 \mathrm{M} \mathrm{HCl} \mathrm{pH}$ $=0.3$ ). The electrochemical samples were polished along with the curved surface before being sealed in epoxy resin leaving only the surface of coatings exposed to solutions. Prior to the tests, the air formed passive film of the working electrodes was cathodically removed by 
polarizing to $-1.2 \mathrm{~V}$ vs SCE for $180 \mathrm{~s}$. Afterward the samples were left at open circuit potential for about $1 \mathrm{~h}$ until the potential had reached a steady state. The potentiodynamic polarizations were carried out at a sweep rate of $0.5 \mathrm{mV} \cdot \mathrm{s}^{-1}$ from $-0.5 \mathrm{~V}$ vs. SCE to $1.1 \mathrm{~V}$ vs. SCE before reversing the potential. Current-time transient tests were determined at $0.6 \mathrm{~V}$ vs SCE (i.e. in the passive region) for 1800 s. Mott-Schottky plots were carried out to evaluate the semiconductor properties of each passive film after immersing the material in $0.50 \mathrm{M}$ $\mathrm{NaCl}$ solution for $1 \mathrm{~h}$. The selected test frequency was $1 \mathrm{kHz}$. EIS tests of different immersing time were examined to evaluate the corrosion resistance of the as-sprayed stress coatings with the exposure time. The steady state measurements of EIS were carried out once a day at the open circuit potential using a sinusoidal potential perturbation of $\pm 10 \mathrm{mV}$ (peak-to-peak amplitude) in a frequency range of $10 \mathrm{mHz}$ to $10 \mathrm{kHz}$. All the measurements were repeated at least three times to ensure good reproducibility.

\subsection{Surface analyzes}

Surface analyzes were conducted on coated specimen that were immersed in $0.50 \mathrm{M}$ $\mathrm{NaCl}$ solution for $24 \mathrm{~h}$. The analyses were carried out by X-Ray Photoelectron spectroscopy (XPS) using ESCALAB250 photoelectron spectrometer with Al $\mathrm{K}_{\alpha}$ excitation $(h v=1486.6 \mathrm{eV})$. Carbon contamination with $\mathrm{C} 1 s$ peak value of $284.6 \mathrm{eV}$ was used to calibrate the binding energies. The standard binding energies of Fe $2 p, \mathrm{Cr} 2 p$, Mo $3 d, \mathrm{Mn} 2 p, \mathrm{~W} 4 f, \mathrm{C} 1 s, \mathrm{O} 1 s$ and $\mathrm{Cl} 2 p$ core levels were referred to NIST XPS database. The in-situ XPS argon-ion beam sputtering was used to obtain the depth profiles of AMC surface. Argon ion sputtering was controlled by power of $2 \mathrm{kV}, 2 \mu \mathrm{A}$ with sputtering rates of $0.05 \mathrm{~nm} \cdot \mathrm{s}^{-1}$ and subsequently the spot area was adjusted to $0.2 \mathrm{~nm} \cdot \mathrm{s}^{-1}$. 


\section{Results}

\subsection{Characterization of the coatings}

\subsubsection{Amorphous characteristics of the coatings}

The XRD phase identification of the AMCs, shown in Fig. 3a, suggests that there is a broad halo peak at $2 \theta=40-50^{\circ}$, along with a few crystalline diffraction peaks in the XRD patterns. These overlapping peaks corroborate the hypothesis that several nanocrystalline phases are present in the amorphous matrix. The XRD diffractogram also suggest that there is a negligible amount of oxides present in the AC-HVAF AMCs, since the oxide phases are known to have a detrimental effect on the formation of the amorphous structure [3]. The crystalline phases present in the $\mathrm{AMCs}$ were identified as $\mathrm{Fe}_{2} \mathrm{C}, \mathrm{Cr}_{7} \mathrm{C}_{3}, \mathrm{M}_{23} \mathrm{C}_{6}$ and $\mathrm{Cr}_{2} \mathrm{~B}$ phases, and exhibited a slightly tendency towards a crystalline microstructure with the increased of residual stress. Furthermore, due to the different sample geometry, there is a different spraying distance which is responsible for the difference amorphous phase content. The low extent of oxide present in the coating sprayed with AC-HVAF compared to HVOF technique is associated with the special spraying characteristics of AC-HVAF method which uses air instead of oxygen. Consequently, the oxidation and thermal deterioration of sprayed materials are significantly reduced and this results in high-impact coatings with extremely low oxide content.

The DSC traces of the ribbon and AMCs are showed in Fig.3b. As observed in Fig.3b, the DSC traces of the ribbon and three coatings displayed an exothermic reaction above the crystallization temperature $\left(T_{x}\right)$; this feature, associate with a decrease in heath flow, is thought to be associated with the precipitation of certain crystalline phases. The fraction of amorphous phase can be calculated using the equation below: 


$$
V_{f}=\Delta H_{\text {coating }} / \Delta H_{\text {ribbon }}
$$

where $V_{f}$ is the fraction of amorphous phase, $\Delta \mathrm{H}_{\text {coating }}$ and $\Delta \mathrm{H}_{\text {ribbon }}$ are the crystallization enthalpies of the AMC and ribbon specimens, respectively. The fraction of amorphous phase of the three AMCs were calculated to be approximately $78.9 \%$ (for $0^{\circ}$ ), $78.1 \%$ (for $110^{\circ}$ ), and $78.5 \%$ (for $60^{\circ}$ ) thus indicating the same amorphous phase contents in the three geometry investigated.

\subsubsection{Microstructure of the coatings}

The SEM images of as-sprayed surface and cross-sectional of AMCs deposited with different tensile residual stresses are shown in Fig. 4. Several well-flattened splat and individual melted particles appear in the uniform structure of as-sprayed coating, as shown in Fig. 4a, 4b and 4c. Several visible pores appear as dark regions near the partially melted powders. The AC-HVAF AMCs all exhibit a layered structure, including several pores formed between the layers (Figs. 4d, 4e and 4f). These structures may have developed due to the self-annealing or adiabatic recoalescence in deposited layers and thus results in the formation of layer-by-layer structure [23]. Interestingly, and as predicted by the XRD characterization, only a few oxide particles were identified in the AC-HVAF AMC. The AC-HVAF AMC appeared stratified with layers of apparently different density and microstructural characteristics with the substrate / coatings interface being more uniform and compact.

\subsection{Electrochemical corrosion behavior}

\subsubsection{Potentiodynamic polarization behavior}

The potentiodynamic polarization curves of AMCs as a function of geometry, residual stress, $\mathrm{pH}$ and temperature are shown in Fig.5. Fig. 5a shows the polarization behavior of the 
AMCs samples with different residual tensile stresses in $0.50 \mathrm{M} \mathrm{NaCl}$ solution. The sample with the lowest residual stress showed a spontaneous passivation with a passive current density of $1 \times 10^{-4} \mathrm{~A} \cdot \mathrm{cm}^{-2}$ and it was also noted that by increasing the residual tensile stress the passive current density increased too. Specifically, the passive current densities changed from $2 \times 10^{-4} \mathrm{~A} \cdot \mathrm{cm}^{-2}$ under tensile residual stress of $1247.93 \mathrm{MPa}$ for Cst1 to $6 \times 10^{-4}$ $\mathrm{A} \cdot \mathrm{cm}^{-2}$ under tensile residual stress of $1461.07 \mathrm{MPa}$ for Cst2. Fig. $5 \mathrm{~b}$ shows the polarization behavior of the AMCs with tensile residual stress of $1247.93 \mathrm{MPa}$ for Cst1 in the chloride-containing solutions at different $\mathrm{pH}$ and it is clear that the passive current densities dramatically increased with acidity. In fact in neutral solution $(0.50 \mathrm{M} \mathrm{NaCl})$ the passive current density was $2 \times 10^{-4} \mathrm{~A} \cdot \mathrm{cm}^{-2}$ but at pH $0.3(0.50 \mathrm{M} \mathrm{HCl})$ the current density was $\sim 1 \times$ $10^{-3} \mathrm{~A} \cdot \mathrm{cm}^{-2}$. Fig. $5 \mathrm{c}$ shows the polarization behavior of the coating in $0.25 \mathrm{M} \mathrm{NaCl}$ acidified to $\mathrm{pH} 0.6(0.25 \mathrm{M} \mathrm{HCl})$ as a function of the temperature. It was found that the temperature can significantly influence the passive behavior of the AMCs and increase their passive current density from $6 \times 10^{-4} \mathrm{~A} \cdot \mathrm{cm}^{-2}$ at $20{ }^{\circ} \mathrm{C}$ to $\sim 8 \times 10^{-3} \mathrm{~A} \cdot \mathrm{cm}^{-2}$ at $80{ }^{\circ} \mathrm{C}$. Despite the significant increase in the passive current density with temperature, at none of the temperature stable pitting corrosion; this finding reflects the strong ability of these amorphous coating to resist localized corrosion. It is noteworthy that the potential at which the current density started dramatically increasing is not associated with pitting corrosion. This value of potential $(\sim 1.1$ vs. SCE for the three curves) is either associated with transpassivity of the passive film, or more likely with the oxygen evolution reaction occurring on the surface of the anodically polarized samples. Finally it is also important to point out that the values of passive current densities reported in these experiments would be too high for materials to be considered passive. However the values of measured currents were normalized to the nominal area 
exposed to the environment and did not take into account the combined effect of surface morphology and porosity which significantly increase the effective area.

\subsubsection{Cyclic polarization behavior}

Cyclic polarization was employed to evaluate the localized corrosion resistance of materials. The stability of the passive film is normally associated with the change in the reversed current density of the cyclic polarization curves, and a smaller hysteresis loop can reflect an enhanced pitting resistance [24]. Fig. 6 shows that, for the AMC of Cts2 (Fig 6c), a larger hysteresis loop is appeared in the cyclic polarization curve compared to Cts0 (Fig 6a) and Cts1(Fig 6b) has an intermediate behavior. However, it is noteworthy remarking that, considering the relatively low hysteresis in each sample, none of these samples showed a fully developed and stable pitting and most likely the hysteresis is associated with a natural change in the surface state following transpassivity or oxygen evolution. It is therefore suggested that not even in the presence of the highest tensile residual stress the sample underwent localized corrosion.

\subsubsection{Current-time curves}

Potentiostatic polarization measurements were conducted to obtain more information about passivation and its breakdown. Fig. 7 shows the typical current-time curves of AMCs whilst being anodically polarized at $0.6 \mathrm{~V}$ versus SCE for $1800 \mathrm{~s}$ in $0.50 \mathrm{M} \mathrm{NaCl}$ solution. Notably, the polarization potential is less than the hysteresis potentials determined from the cyclic polarization curves (Fig. 6a, 6b, and 6c). Several current transients, characterized by sharp peaks, were detected on the AMCs of Cts1 (intermediate residual stress) and more clearly on sample Cts2 (had the highest residual stress). These micro-transients in the 
current-time curve can be associated to metastable pits originated from the local breakdown of the passive film [25-26]. Compared with that in the AMC of Cts2, the microtransients in the $\mathrm{AMC}$ of $\mathrm{Cts} 0$ were clearly less frequent and smaller. This finding reflects that the local breakdown of the passive film, is inhibited in the AMC of Cts0 and it is accelerated by the appearance of high residual stresses.

\subsubsection{Mott-Schottky plots}

Mott-Schottky plot represents the function of electrode capacitance with the electrode potential, which can evaluate the electronic properties of a passive film. Generally, the capacitance of the passive film, $C_{f}$, is consist of three capacitances [27]:

$$
\frac{1}{C_{f}}=\frac{1}{C_{M}}+\frac{1}{C_{S C}}+\frac{1}{C_{d l}}
$$

where $C_{M}$ is the capacitance of metal/film interface, $C_{S C}$ is the capacitance of space charge, and $C_{d l}$ is the capacitance of Helmholtz double layer. For the relatively thick space charge layer, the $C_{S C}$ is minimal and the contributions of $C_{M}$ and $C_{d l}$ can be neglected. Hence, $C_{f}$ is taken as $C_{S C}$. The semiconducting behaviour of the depletion region of passive film can be reflected by the plots of $1 / C_{S C}{ }^{2}$ versus $E$. The $C_{S C}$ of an n-type semiconductor can be calculated by the equation below:

$$
C_{S C}^{-2}=\frac{2}{\varepsilon_{r} \varepsilon_{0} e N_{D}}\left(E-E_{F B}-\frac{k T}{e}\right)
$$

where $\varepsilon_{r}$ is the film dielectric constant (the $\varepsilon_{\mathrm{r}}$ of $\mathrm{Fe}-\mathrm{Cr}$ alloyis 15.6 [28]), $\varepsilon_{0}$ is the vacuum permittivity constant, $e$ is an electron charge, $N_{D}$ is the donor density, $E$ is the applied potential, $E_{F B}$ is the flat band potential, $k$ is the Boltzmann constant, and $T$ is the temperature.

Fig.8 represents the Mott-Schottky curves of passive films formed on AMCs at different potentials in $0.50 \mathrm{M} \mathrm{NaCl}$ solutions. In all solutions the AMCs exhibited an obvious linear regions within a certain potential range and the positive slope in the linear region reflects that the semiconductor of the passive film is an n-type. $N_{D}$ values can be obtained from the 
slope of the linearly fitted plots and expressed as follows:

$$
N_{D}=\frac{2}{\varepsilon_{r} \varepsilon_{0} e}\left(\frac{\mathrm{d} C_{S C}^{-2}}{\mathrm{~d} E}\right)^{-1}
$$

The donor densities obtained by Eq. (3) are presented in Fig. 8. When immersed in the $0.50 \mathrm{M}$ $\mathrm{NaCl}$ solution, the AMCs of Cts0, Cts1 and Cts2 had $N_{D}$ values on the order of magnitude of $10^{22}-10^{23} \mathrm{~cm}^{-3}$ and these values are consistent with what expected for stainless steels and Fe-Cr alloys $\left(10^{20}-10^{22} \mathrm{~cm}^{-3}[5,28-29]\right)$. The $N_{D}$ values increased from Cts0 (lowest residual stress), Cts1 to Cts2 (highest residual stress). These results agree with the observation obtained from the polarization curves (Fig. 5, Fig. 6) and current-time curves (Fig. 7) obtained in chloride-containing solutions. The results also strongly suggest that the stability of the passive films of AMCs are significantly influenced by the donor density.

\subsection{Immersing corrosion behavior}

EIS tests with different exposure time were conducted to estimate the corrosion resistance of the tensile residual stress coatings. Representative Nyquist and Bode plots of AMCs with different exposure periods in $0.50 \mathrm{M} \mathrm{NaCl}$ solution are shown in Fig. 9. For EIS data simulation, general equivalent circuit model of two sub-electrochemical interfaces is adopted, shown in Fig. 10a, and used to fit the data for Cts0 and Cts1. For the equivalent circuit, $R_{S}$ is the solution resistance, $C P E-c$ paralleled with $R_{p}$ (pore resistance) represents the coatings dielectric properties, $C P E-d$ (capacitance of the double layer) paralleled with $R_{t}$ (reaction resistance at the metal/coating interface) represents the charge transfer process at the coating/steel interface. For the equivalent circuit of Fig.10b, which was used to fit the data for Cts 2 only, $Z w$ (the EIS element of oxygen diffusion) in series with $R_{t}$ is adopted to describe Warburg impedance. The fitting errors for each condition were almost smaller than $10 \%$. The 
dotted line in Fig. 9 reveals the fitting results based on the models, which fits very well over a wide range of frequencies.

For the AMC of Cts0 immersed in solution for a certain period of time, the impedance and phase angle obviously varied. High $|Z|$ values in the high-frequency region reflect high corrosion resistance of materials. Based on the $|Z|$ values in the high-frequency region (Figs. 9b, 9d and 9f), the $|Z|$ values of all three AMCs during the six-day immersion test decreased with the time. The inferior corrosion resistance of the AMCs with time is associated with the uncompact nature of the coating. The phase angle values can also affect the overall corrosion process [30]. The interfacial corrosion process is always related to the reduction of low frequencies phase angle. The initiation of film degradation of AMCs can be judged from the decrease of the capacitive character. The variation of phase angle with the exposure time for three AMCs exhibits similar tendency, as represented in Figs. 9b, 9d and 9f.

For the AMC of Cts0, the propagation of pitting corrosion results in the gradual formation of corrosion product and preventing the mass transfer process of the pores. Almost no evident rust was observed after the six-day exposure time, whereas only a few corrosion products were observed in several local regions (Fig. 11a). This finding indicates that no degradation occurred during the exposure time, which is in contrast to the findings for the other coatings [5]. For the AMCs of Cts1 and Cts2, no corrosion products were observed during the exposure time, and evident localized corrosion cracks (encircled in Figs. 11b and 11c) occurred on the coating surface after a six-day exposure period. This finding reflects the localized failure of the residual stress during a six-day immersion test, which derives from the water/ion penetration to the microcracks. The high residual stress promotes microcracks to form and open which are subsequently saturated with electrolyte. Consequently, coating with 
a higher residual stress develops more corrosion products on the surface over time (Figs. 11b and 11c). These results are consistent with the EIS results.

\section{Discussion}

\subsection{The correlation of uniform corrosion with the tensile residual stresses}

Many factors, such as thermal history and deposition parameters, make it uneasy to compare the corrosion performance of coatings obtained from other sources. However, the progressive deposition model of plasma-sprayed coatings provides a suitable framework for explaining the "theoretical" variation of residual stress with thickness [31]. Stresses detected on thick substrates surface are relatively homogeneous across the coating surface [9,32]. In addition, residual stresses of the coatings strongly dependent on spray particle velocity [9,14,33], spray distance and oxygen-to-fuel ratio [34]. Peening stresses typically dominate HVOF coatings because of high spray particle velocity (up to $1,000 \mathrm{~m} \cdot \mathrm{s}^{-1}$ ) [9] and relatively low temperature (from $1,500{ }^{\circ} \mathrm{C}$ to $1,800{ }^{\circ} \mathrm{C}$ ) [35]. High velocities of the spray particle can lead to the formation of coatings with more compressive residual stresses [9,36-37] which have the benefit of improving mechanical properties, such as fatigue life and bonding strength. Whilst the AC-HVAF has almost the same spraying process as HVOF, however since the oxygen is replaced to air to give economical benefits, there is an effect on particle temperature and kinetics. In the AC-HVAF process, spray particles are heated under melting temperature while being accelerated to a typical velocity of $700-850 \mathrm{~m} \cdot \mathrm{s}^{-1}$, forming a coating upon impact on a substrate [18-19]. Therefore, due to the lower velocity of particles in HVAF, a lower peening effect is present and high residual tensile residual stresses can be generated on the surface of HVAF coating, as indicated in this research. The effect of tensile residual stress can 
be detrimental and lead to coating cracking and promote fatigue failure.

The tensile residual stresses deteriorated the uniform corrosion resistance of the AMCs. This finding is consistent with the results obtained from potentiodynamic polarization values (Fig. 5). The high tensile residual stress of AMCs exhibits a higher passive current density than that of the low high tensile residual stress. The passivation densities of AMCs were also found to be sensitive to $\mathrm{pH}$ values and temperature. As shown in Fig. 4, the AC-HVAF AMCs exhibit an unstable structure with a few porosities existing in the layer. Previous studies $[5,6,8]$ have showed that, for thermal-sprayed coatings, the pores have a significant impact on its high passive current densities. It is nonetheless important to point out that in the electrochemical test the values of measured currents were normalized to the nominal area exposed to the environment and did not take into account the combined effect of surface morphology and porosity which significantly increase the effective area. The pores can facilitate aggressive ions, such as chloride ions penetrating into the layer, thus accelerating the uniform corrosion process. Furthermore, due to the occluded morphology, the porosity can be considered as micro sites where micro pitting would occur. However, in this study, the three AMCs are prepared under the same spraying condition and exhibit a comparable value of porosities. Therefore the increase in passive current densities between samples cannot be easily attributed to the porosity.

Furthermore, damage is caused by the attack of chloride ions, whereas protection occurs at the same time on the surface of the coatings because of the formation of corrosion product films. Few researchers suggested the anodic regions usually correspond to areas with the tensile stress [38] probably because the tensile stresses can increase the localized surface reactivity [39]. This hypothesis is consistent with the findings shown in Fig. 5a. Furthermore, 
the open circuit potential of the AMCs was slightly lower in those samples with increased tensile residual stress, which indicates that the tensile residual stresses accelerate corrosion susceptibility. Finally it was recorded that the $|Z|$ values in the high-frequency region of all the three coatings decreased with the exposure time (Figs. 9b, 9d and 9f), thus suggesting a deterioration of the corrosion resistance of the AMCs.

\subsection{The correlation of localized corrosion resistance with the tensile residual stresses}

From the potentiodynamic polarization curves there was no evidence of the formation of stable pitting in either sample, irrespective of the value of residual stress. However, in cyclic polarization curves, the high tensile residual stress of AMC showed a larger hysteresis loop when the potential was reversed (Fig. 6) which however it is improbably associated with pitting but more likely with local surface variation following oxygen evolution or transpassivity. In any case, if this hysteresis was associated with pitting, it would also imply that these coatings have a very high repassivation potential too.

Most interestingly, many intermittent anodic current spikes can easily be distinguished from the current-time curves (Fig. 7). These current spikes reflect metastable pitting and occur preferentially in the samples with the highest tensile residual stresses were the highest. This could be rationalized considering the fact that at higher tensile stress more microcracks near the pores and unmelted particles can form (Fig. 11) and these regions can be preferential sites for metastable and localized corrosion events. Conversely, the low tensile residual stress of the AMC exhibiting a stronger ability to withstand metastable pitting corrosion most likely originates from the stable passive film acting as a barrier that prevents the aggressive ions transferring to the alloy surface. 
The possibility of localized corrosion can also be deduced from the variation of the phase angle with time in the Bode plots (Figs. 9b, 9d and 9f). The occurrence of the second time constant at low frequencies of the phase angle can reflect that the initiation and propagation of pitting corrosion during the immersion period. As shown in Figs. 9d to 9f, in contrast to the AMC of Cst0, two time constants for the AMCs of Cts 1 and Cts 2 exist in the entire exposure period. In particular, for Cts2, the diameter of the first capacitive loop significantly increased as the immersion time increased, and the linear part (Warburg impedance) of the low-frequency region appeared (Fig. 9e). This phenomenon showed that the protectiveness of the film degraded. The Warburg impedance is related to the absorption of the corrosive ions, such as chloride ions. The time dependence of the charge transfer resistance $\left(R_{t}\right)$ and double layer capacity $(C P E-d)$ reveals that the $R_{t}$ and $C P E-d$ values decreased with the increase in tensile residual stress and time, which indicates that the residual stress aggravates the localized dissolution process of the AMCs.

\subsection{The correlation of localized corrosion resistance with the stability of passive film}

The uniform and localized corrosion resistance of a material is dictated by the nature of the passive film. Therefore, the lower localized corrosion resistance of the high tensile residual stress may be related to the characteristics of the stability of passive film. To investigate this hypothesis, XPS was used to analyze the growth passive film on the AMCs surface. Fig. 12 shows the XPS spectra of materials formed in $0.50 \mathrm{M} \mathrm{NaCl}$. TheFe, Cr, Mo, $\mathrm{Mn}, \mathrm{W}, \mathrm{O}$, and $\mathrm{C}$ peaks are detected on spectra. Judged from the peak strength, the component of the film is mainly composed of $\mathrm{Fe}, \mathrm{Cr}, \mathrm{Mo}$, and Mn elements. Therefore, the presence of Mo and $\mathrm{W}$ in the film, especially the Mo enrichment, can attribute to the stable passive film. 
[6-7]. Some dominating peaks are marked in the spectra, which indicate the presence of the same elements both in the three AMCs, considering the position and strength of each peak.

Differences occur in the depth profiles of the elements, as shown in Fig. 13. The content of each element was calculated from the integrated intensity of the peak for individual species. The Mo, Mn and $\mathrm{W}$ content corresponds to their own metallic compounds, whereas the oxygen content corresponds to all the species. Mo, Mn and $\mathrm{W}$ were apparently depleted in the passive film compared to the alloy of nominal compositions. The thickness of the passive film, estimated from the variation the oxygen content [40], was approximately 1,2 and $3 \mathrm{~nm}$ for Cts0, Cts1 and Cts2 respectively. Specifically, the coating with highest tensile residual stress exhibited a thicker passive film; consequently its passive film must have been less protective to be able to grow much thicker than on the other samples during the same exposure time. A thicker film can lead to a high resistance to corrosion [41] but only providing that its characteristic are unchanged during its growth. It is also possible that the relatively large thickness variation recorded in each sample is due to artefact associated with topographical variation as mentioned above.

The composition of the passive film can also be obtained from the XPS spectra. Fig. 14 shows the spectra of $\mathrm{Fe} 2 p, \mathrm{Cr} 2 p, \mathrm{Mo} 3 d, \mathrm{Mn} 2 p, \mathrm{~W} 4 f$ and $\mathrm{Cl} 2 p$ for the $\mathrm{AMC}$ after Ar ion sputtering for $20 \mathrm{~s}$. For three AMCs, the spectra of the each element from the underlying surface consist of the same peaks but with different peak intensities. As shown in Fig. 14a, the $\mathrm{Fe} 2 p$ spectrum is consist of $\mathrm{Fe} 2 p 1 / 2$ and $\mathrm{Fe} 2 p 3 / 2$ peaks corresponding to the metallic $(\mathrm{Fe})$ and oxide $\left(\mathrm{Fe}^{2+}\right.$ and $\left.\mathrm{Fe}^{3+}\right)$ states. The $\mathrm{Cr} 2 p 1 / 2$ and $\mathrm{Cr} 2 p 3 / 2$ peaks are shown in Fig. $14 \mathrm{~b}$, which represent the metallic $(\mathrm{Cr})$ and oxide $\left(\mathrm{Cr}^{3+}\right.$ and $\left.\mathrm{Cr}^{6+}\right)$ states. The Mo3d peaks of the metallic (Mo) and oxide $\left(\mathrm{Mo}^{4+}\right.$ and $\left.\mathrm{Mo}^{6+}\right)$ states, the $\mathrm{Mn} 2 p$ peaks of the metallic (Mn) and oxide 
$\left(\mathrm{Mn}^{2+}\right.$ and $\left.\mathrm{Mn}^{4+}\right)$ states, and the $\mathrm{W} 4 f$ peaks of the metallic $(\mathrm{W})$ and oxide $\left(\mathrm{W}^{4+}\right.$ and $\left.\mathrm{W}^{6+}\right)$ states, are shown in Figs. 14c, 14d and 14e, respectively.

It is important to bear in mind the limitation of this XPS; this analytical technique has a very high depth resolution but a relatively poor spatial resolution. Consequently, if the area analyzed is not perfectly flat, due to the topographical variation uneven sputtering can occur and the metallic state be detected in the oxide. Therefore the presence of metallic phases in the passive film is an artefact. Figure 15 shows the cationic and atomic fractions of the oxidised species detected by XPS. All passive films of AMCs mainly contain $\mathrm{Fe}^{2+} / \mathrm{Fe}^{3+}$, $\mathrm{Cr}^{3+} / \mathrm{Cr}^{4+}, \mathrm{Mo}^{4+} / \mathrm{Mo}^{6+}$ and other species. The high valence stages of $\mathrm{Fe}, \mathrm{Cr}$, and Mo cations aggregate in the passive film out layer from some oxides. The structure of the passive film consists of a bilayer structure of defective outer layer and inner layer, e.g. high-valence species and low-valence species [7-8,26]. These results indicate that the oxide compositions and the elements distribution in the passive films are nearly identical and therefore the composition of the passive film does not appear to have a direct role in determining the localized corrosion resistance of the AMCs.

The stability of the passive film is influenced by its electronic properties, which can be determined from the M-S curves (Fig. 8). The stability of passive films for Fe-based alloys in many solutions is related to its semiconductor properties $[5,26,40]$. On the basis of the point defect model [42], the donors are the defects of the oxygen vacancies generated at the metal/oxide interface. Therefore, the lower $N_{D}$ value of the AMC of Cts0 reflects that the few yet dense defect structures of passive films lead to the enhanced corrosion resistance. The inferior passive performance of the AMCs of Cts 1 and Cts2 could be associated with the increase in $N_{D}$ value and results in the increasing defects concentration in the passive film. 
Besides, a higher donor density corresponds to a higher conductivity of the passive film [43]. The passive current density is also determined by ion conductivity. The high $N_{D}$ value of the AMCs of Cts1 and Cts2 indicates that the ions are transported easily in the passive film formed in these two coatings, which is more susceptible to aggressive ions, such as $\mathrm{Cl}^{-}$. This will also increase the tendency of metastable pitting and localized corrosion. The XPS spectra of $\mathrm{Cl} 2 p$ formed on three AMCs are presented in Fig. 14f. The intensity of the $\mathrm{Cl} 2 p 3 / 2$ peak can be identified in the three $\mathrm{AMCs}$, indicating that $\mathrm{Cl}^{-}$ions participating the formation of the passive film, which is consistent with the previous results $[6,43]$. The presence of chloride ions on the passive film results in a concentration gradient and accelerates its diffusion into the film, which stabilize the local acidification generated from metal cations hydrolysis thus leading to active dissolution of the passive film [44]. This phenomenon agrees well with the chloride penetration mechanism [45] that corresponding to the structure of the passive film, particularly the stability of the passive film. Therefore, the decreased localized corrosion resistance of the passive film that formed on the high residual tensile stress AMCs is expected to be associated with a higher defect concentration (e.g. lower $N_{D}$ value).

As a final remark, Fe-based AMCs are predominantly designed and developed to exhibit both high corrosion resistance and good mechanical performance. Since residual tensile stresses might also have an implication on the abrasive wear resistance, the influence of residual tensile stress on abrasive wear resistance of the Fe-based AMCs will be elaborated in future studies.

\section{Conclusions}

(1) The residual stresses of Fe-based AMCs were determined by the mechanical method 
and calculated from the curvature of coating by using sharp indentation testing. The surface residual stress of the as-sprayed AMC is tensile and this could be caused by the characteristics of the AC-HVAF method as well as the geometry of the sample. In fact it was found that the greater the convex arc of the substrate, the higher the tensile residual stresses was.

(2) The AMCs which had high tensile residual stress exhibited a higher passive current density than that those with low tensile residual stress. It is postulated that the tensile residual stresses accelerates the localized corrosion susceptibility of the AMCs near the pores and unmelted particles by forming microcracks and promoting fast diffusion path for chloride ions.

(3) The stability of the passive films formed on the AMCs is related to the composition and structural properties of the film. A slight compositional difference was observed in the films of the three tensile residual stress AMCs. However, the higher donor density of the passive film formed on the high tensile residual stress AMC might also be responsible for the lower localized corrosion resistance.

\section{Acknowledgements}

This work was supported by the National Science Foundation of China (under grant Nos. 51274151 and 51401051), China Postdoctoral Science Foundation (No.2014M551447), Natural Science Foundation of Heilongjiang Province (No.QC2013C056). 


\section{References}

[1] J.C.Farmer, J.J.Haslam, S.D.Day, T.Lian, C.K.Saw, P.D.Hailey, J.S.Choi, R.B.Rebak, N.Yang, J.H.Payer, J.H.Perepezko, K.Hildal, E.J.Lavernia, L.Ajdelsztajn, D.J.Branagan, E.J.Buffa, L.F.Aprigliano. J.Mater.Res. 22(2007) 2297-2311.

[2] H.S. Ni, X.H. Liu, X.C. Chang, W.L. Hou, W. Liu, J.Q. Wang. J.Alloy.Compd. 46(2009)163-167.

[3] J. Farmer, J.-S. Chol, C. Saw, J. Haslam, D. Day, P. Hailey, T. Lian, R. Rebak, J.Perepezko, J. Payer, D. Branagan, B. Beardsley, A.D. Amato, L. Aprigliano. Metall.Mater. Trans. A 40A (2009) 1289-1305.

[4] Y.Peng, C.Zhang, H.Zhou, L.Liu. Surf.Coat.Technol.218(2013)17-22.

[5] Y. Wang, S.L. Jiang, Y.G. Zheng,W. Ke, W.H. Sun, J.Q. Wang. Surf.Coat.Technol.206(2011)1307-1318.

[6] Y.Wang, Y.G.Zheng, W.Ke, W.H.Sun, W.L.Hou, X.C.Chang, J.Q.Wang. Corros.Sci. 53(2011)3177-3185.

[7] Z.B.Zheng, Y.G.Zheng, W.H.Sun, J.Q.Wang. Corros.Sci.76(2013)337-347.

[8] Y. Wang, Z.Z.Xing, Q.Luo, A.Rahman, J.Jiao, S.J.Qu, Y.G.Zheng, J.Shen. Corros.Sci. 98 (2015) $339-353$.

[9] T.C.Totemeier, R.N.Wright, W.D.Swank. Metall.Mater.Trans.A 35A(2004)1807-1814

[10]T.W.Clyne, S.C.Gill. J.Therm.Spray Technol.5(1996)401-418.

[11]J.Matejicek, S.Sampath, P.C.Brand, H.J.Prask. Acta Mater.47(1999)607-617.

[12]L.Pejryd, J.Wigren, D.J.Greving, J.R.Shadley, E.F.Rybicki. J.Therm.Spray Technol.4(1995)268-274.

[13]T.C.Totemeier, J.K.Wright. Surf.Coat.Technol. 200(2006)3955-3962.

[14]A.J. Allen, M.Bourke, S.Dawes, M. T.Hutchings, E J.Withers. Acta Metall.41(1992) $2361-2374$

[15]D.J.Greing, E.F.Rybicki, J.R.Shadley. J.Therm.Spray Technol. 3(1994)379-388. 
[16]M.Wenzelburger, D.Lopez, R.Gadow. Surf.Coat.Technol. 201(2006)1995-2001.

[17]O.Kesler, M.Finot, S.Suresh, S.Sampath. Acta Mater. 45(1997)3123-3134.

[18]D.W.Parker, G.L.Kutner. Adv.Mater.Process 139 (1991) 68-74.

[19] S.Matthews, B.James, M.Hyland. Surf.Coat.Technol. 203(2009)1086-1093.

[20]S.Suresh, A.E.Giannakopoulos. Acta Mater. 46(1998)5755-5767.

[21]S.Carlsson, P. - L.Larsson. Acta Mater.49(2001)2179-2191.

[22]T.Y.Tsui, W.C.Oliver, G.M.Phar. J.Mater.Res.11(1996)752-759.

[23]S. Sampath, H. Herman. J. Therm. Spray Technol. 5(1996)445-456.

[24]W. H. Peter, R. A. Buchanan, C. T. Liu, P. K. Liaw, M. L. Morrison, J. A. Horton, C. A. Carmichael, J. L. Wright. Intermetallics 10(2002)1157-1162.

[25] Y.Kobayashi, S.Virtanen, H.Bohni. J.Electrochem.Soc. 147(2000)155-159.

[26]Z.M.Wang, J.Zhang, X.C.Chang, W.L.Hou, J.Q.Wang. Corros.Sci. 52(2010) 1342-1350.

[27]E.M.A.Martini, I.L.Muller. Corros.Sci.42(2000)443-454.

[28] A.M.P.Simmões, M.G.S.Ferreira, B.Rondot, M.D.C.Belo. J.Electrochem.Soc. 137(1990) 82-87.

[29] Y. Wang, S.L. Jiang, Y.G. Zheng, W. Ke, W.H. Sun, J.Q. Wang. Corros.Sci.63 (2012) 159-173.

[30]B.R.W.Hinton, D.R.Arnott, N.E.Ryan. Mater.Forum 9(1986)162-173.

[31]C.Lyphout, P.Nylen,J.Wigren. ITSC, (2007)588-593.

[32] Y.C.Tsui, T.W.Clyner. Thin Solid Films. 306(1997)23-33.

[33]R.T.R.McGrann, D.J.Greving, J.R.Shadley, E.F.Rybicki, T.L.Kruecke, B.E.Bodger. Surf. Coat. Technol. 59(1998)108-109.

[34]S.Nourouzi, M.Jalali Azizpour, H.R.Salimijazi. Mater.Manuf.Process 29(2014)1117-1125.

[35]S.Kuroda, Y.Tashiro, H.Yumoto, S.Taira, H.Fukanuma, S.Tobe. J.Therm.Spray Technol. 10(2001)367-374.

[36]J.Stoke, L.Looney. Surf.Coat.Technol. 18 (2004) 177-178.

[37]H.J.C.Voorwald, R.C.Souza, W.L.Pigatin, M.O.H.Cioffi. Surf.Coat.Technol.190(2005)155-164. [38]G.Van Boven, W.Chen, R.Rogge. Acta Materialia. 55(2007)29-42. 
[39]R.K.Zhu, J.L.Luo. Electrochem.Commun. 12(2010)1752-1755.

[40]S.Virtanen, P.Schmuki, A.J.Davenport, C.M.Vitus. J. Electrochem. Soc. 144 (1997)198-204.

[41]G.T. Burstein, P.I. Marshall. Corros. Sci. 24 (1984) 449-462.

[42]D.D.Macdonald. J.Electrochem.Soc.139(1992)3434-3449.

[43] S. Virtanen, E.M. Moser, H. Bohni. Corros. Sci. 36 (1994) 373-384.

[44]S. Ningshen, U. Kamachi Mudali, V.K. Mittal, H.S. Khatak. Corros. Sci. 49 (2007)481-496.

[45]C.-O.A. Olsson, D. Landolt. Electrochim. Acta 48 (2003) 1093-1104. 
Table 1 Spraying parameters employed in the AC-HVAF process

\begin{tabular}{l|l}
\hline Parameters & Values \\
\hline Particle size / mesh & $\leqslant 325$ \\
Spray distance / mm & 180 \\
Powder feeding rate / g. $\mathrm{min}^{-1}$ & 3 \\
Turntable rate / $\mathrm{r} \cdot \mathrm{min}^{-1}$ & 133 \\
Reciprocal time /cycle & 10 \\
Air Pressure /psi & 82 \\
Fuel Pressure /psi & 70 \\
\hline
\end{tabular}


Table 2 Parameters and residual stress values of the AMCs

\begin{tabular}{l|l|l|l|l|l|l}
\hline No. & $\begin{array}{l}\alpha \\
\left({ }^{\circ}\right)\end{array}$ & $\begin{array}{l}a \\
(\mathrm{~mm})\end{array}$ & $\begin{array}{l}r \\
(\mathrm{~mm})\end{array}$ & $\mathrm{C}$ & $\begin{array}{l}\text { Hardness } \\
(\mathrm{HV})\end{array}$ & $\begin{array}{l}\text { Residual stress } \\
(\mathrm{Pa})\end{array}$ \\
\hline Cts0 & 0 & 10 & $\infty$ & 1.028 & $827 \pm 34$ & $49.26 \pm 2.04$ \\
Cts1 & 110 & 10 & 6.11 & 1.273 & $711 \pm 25$ & $1247.93 \pm 43.87$ \\
Cts2 & 60 & 10 & 10 & 1.308 & $601 \pm 28$ & $1461.07 \pm 68.11$ \\
\hline
\end{tabular}




\section{Figure captions}

Fig. 1 Dimension of the as-sprayed AMCs

Fig. 2 Influence of the dimensional stress field on the shape of the indentation (arrows parallel to the axial direction)

Fig. 3 XRD patterns (a) and DSC traces (b) of the AMCs

Fig. 4 Surface metallographic images of (a) Cts0, (b) Cts1 and (c) Cts2 and cross-sectional image of (d) Cts0, (e) Cts1 and (f) Cts2 deposited on 316L SS (The percentage represent the porosity of the coatings)

Fig. 5 Potentiodynamic polarization curves of the AMCs under different conditions: (a) different tensile stresses, (b) different concentrations of $\mathrm{H}^{+}$and (c) different temperatures

Fig. 6 Cyclic polarization curves of (a) Cts0, (b) Cts1 and (c) Cts2 AMCs in the $0.50 \mathrm{M} \mathrm{NaCl}$ solution

Fig. 7 Typical examples of current-time transients for AMCs in the $0.50 \mathrm{M} \mathrm{NaCl}$ solution

Fig. $8 \mathrm{M}-\mathrm{S}$ plots of AMCs at various polarization potentials tested in the $0.50 \mathrm{M} \mathrm{NaCl}$ solution

Fig. 9 EIS and Bode plots for [(a) and (b)] Cst0, [(c) and (d)] Cst1 and [(e) and (f)] Cst2 AMCs as functions of immersion time in the $0.50 \mathrm{M} \mathrm{NaCl}$ solution

Fig. 10 General model of an equivalent circuit proposed to conduct curve fitting for the EIS data

Fig. 11 Micrographs of (a) Cts0, (b) Cts1 and (c) Cts2 AMCs after the immersion test

Fig. 12 XPS survey spectra in passive films on AMCs formed in the $0.50 \mathrm{M} \mathrm{NaCl}$ solution

Fig. 13 Depth profiles of alloying components in passive films of AMCs formed in the $0.50 \mathrm{M} \mathrm{NaCl}$ solution

Fig. 14 XPS spectra of (a) Fe2p, (b) Cr2p, (c) Mo3d, (d) Mn2p, (e) W4f and (f) Cl2p (the depth 
profile spectra) for the surface of AMCs after Ar ion sputtering for $20 \mathrm{~s}$, where the sample was immersed in the $0.50 \mathrm{M} \mathrm{NaCl}$ solution for $24 \mathrm{~h}$

Fig. 15. Cationic fractions of the oxidised species detected by XPS from the surface (without Ar-ion sputtering) and the underlying surface of Cts0 (a), Cts1(b), Cts2 (c) in $0.50 \mathrm{M} \mathrm{NaCl}$ solutions, and (d) cationic fractions of the oxidised species on the surface without Ar-ion sputtering. 

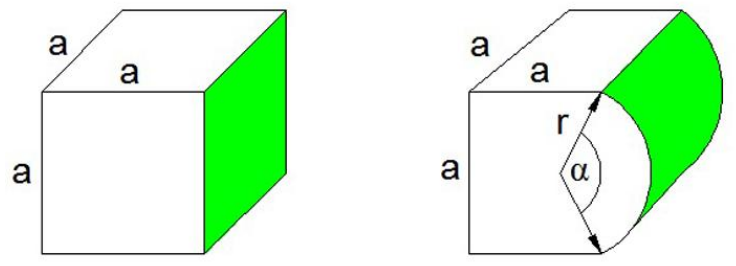

(a)

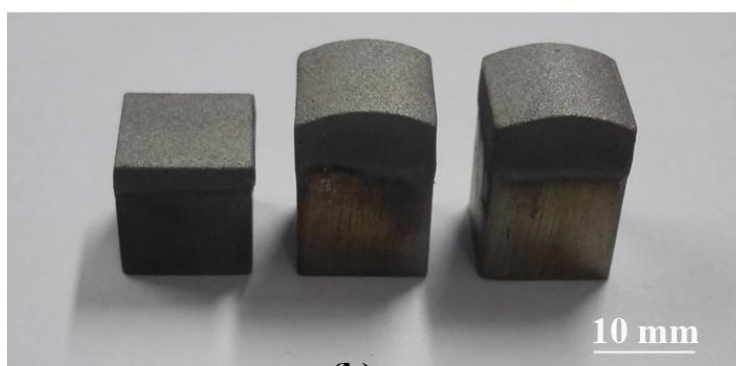

(b)

Wang et al./Fig.1 

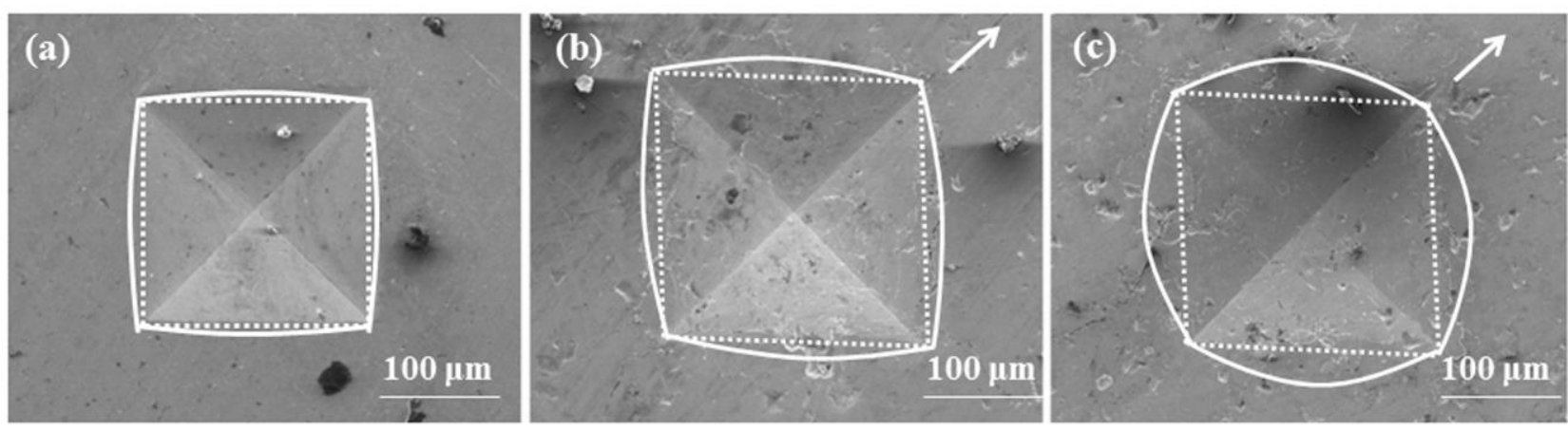

Wang et al./Fig.2 

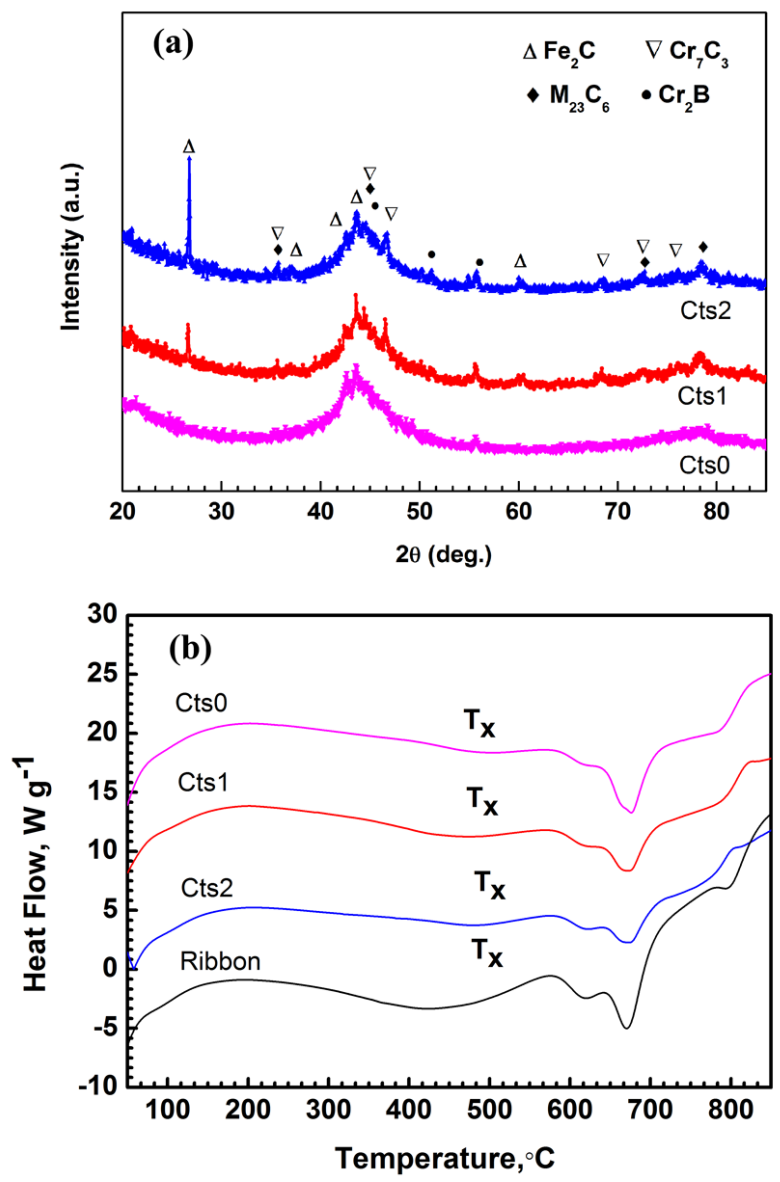

Wang et al./Fig.3 

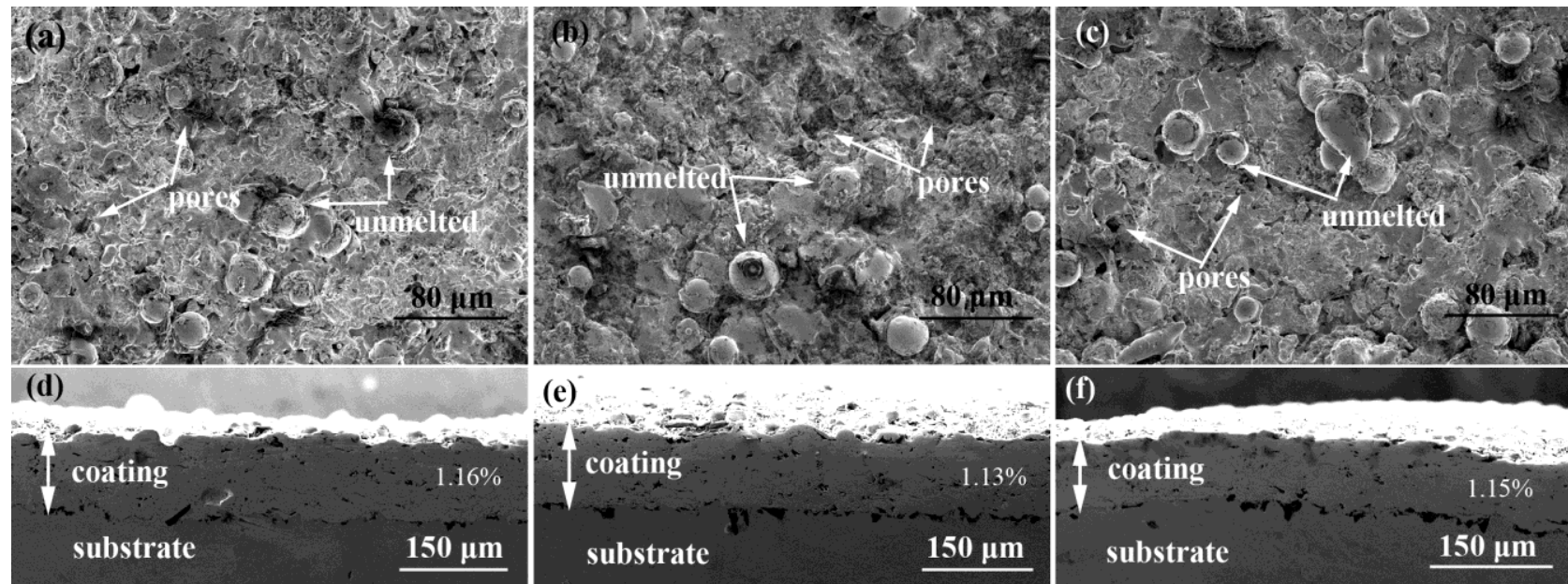

(i)

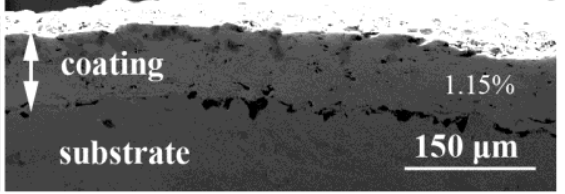

Wang et al./Fig.4 

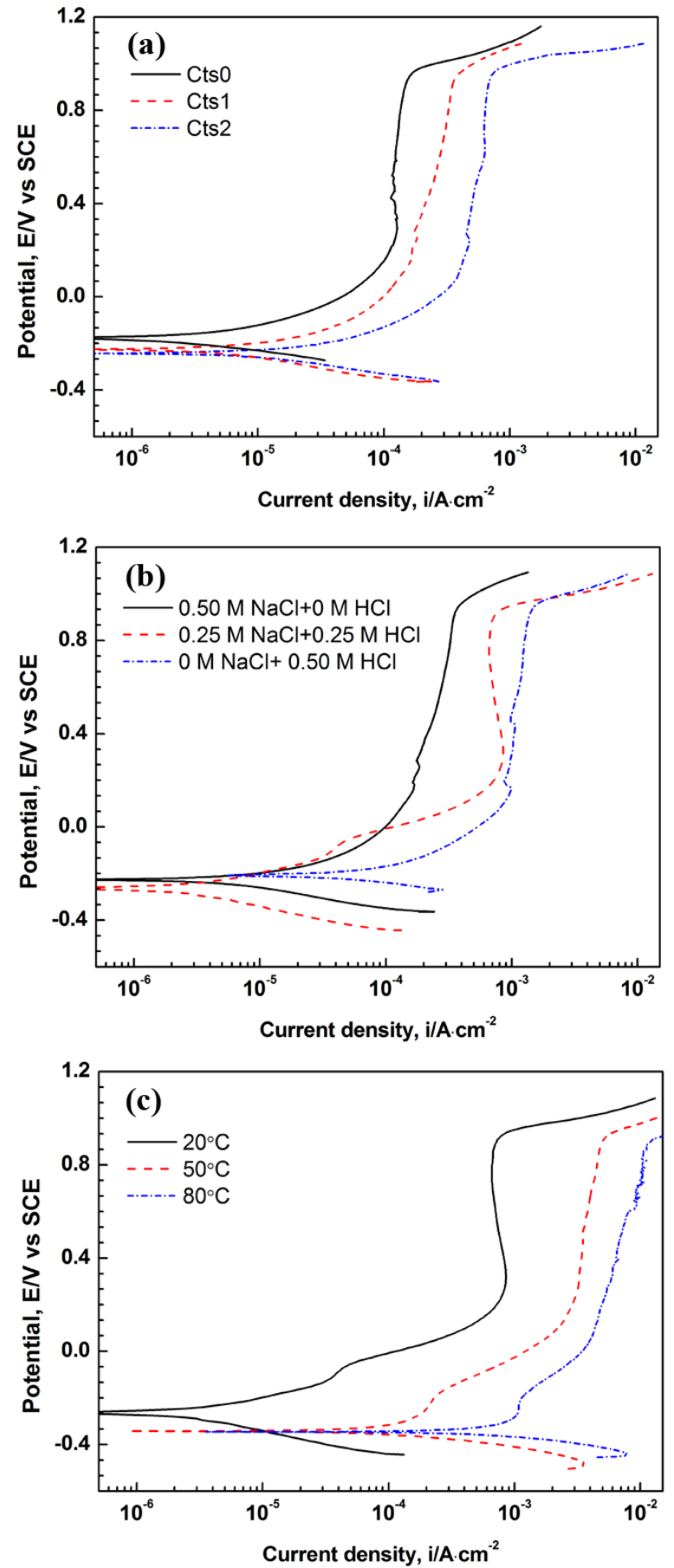

Wang et al./Fig.5 

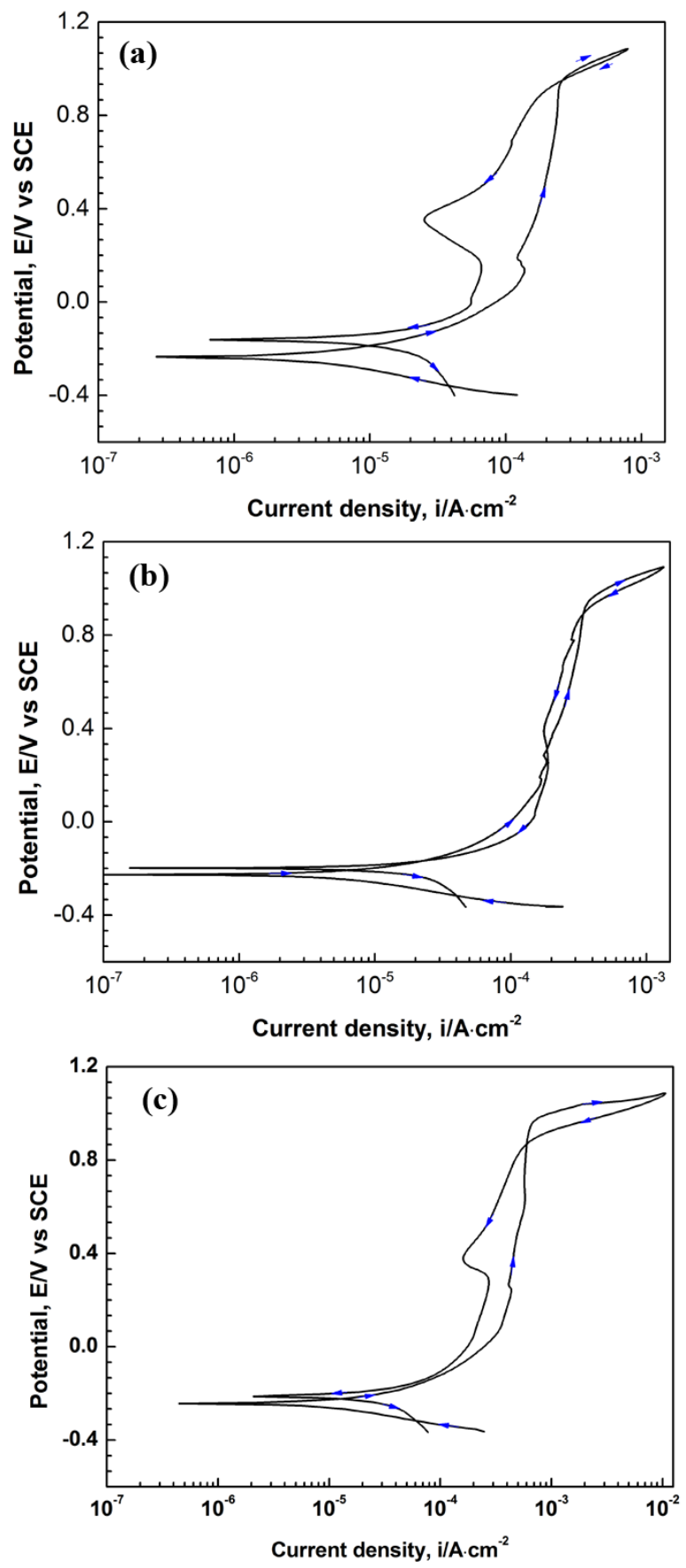

Wang et al./Fig.6 


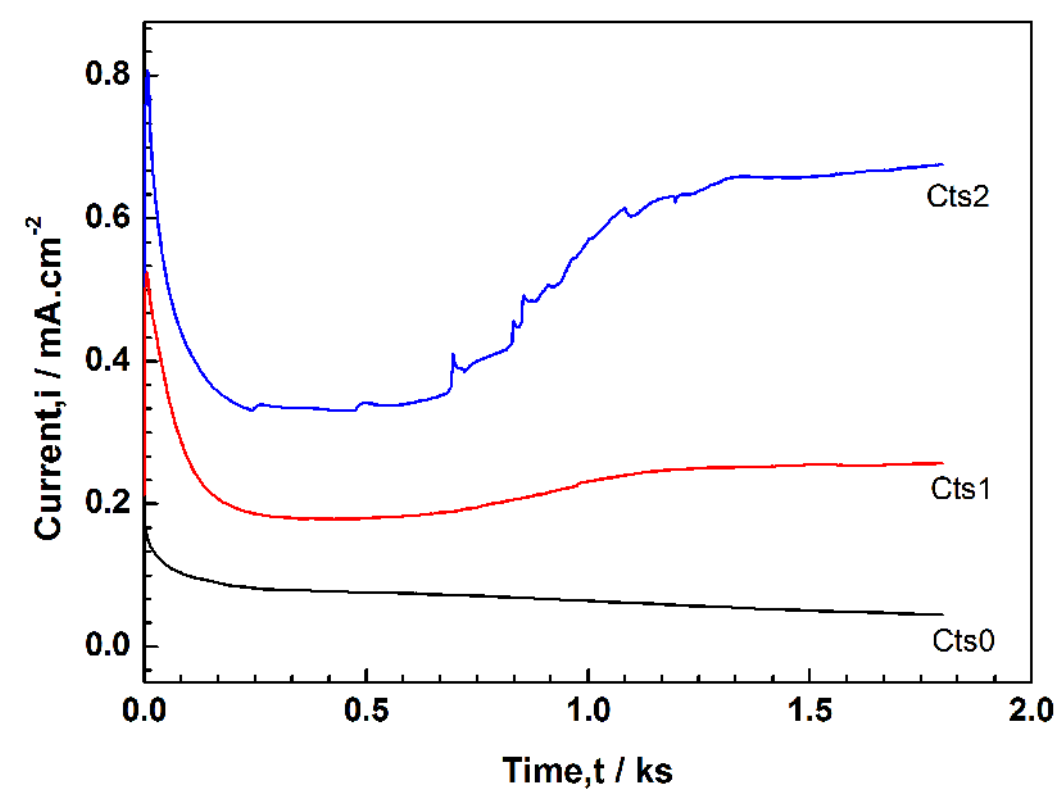

Wang et al./Fig.7 


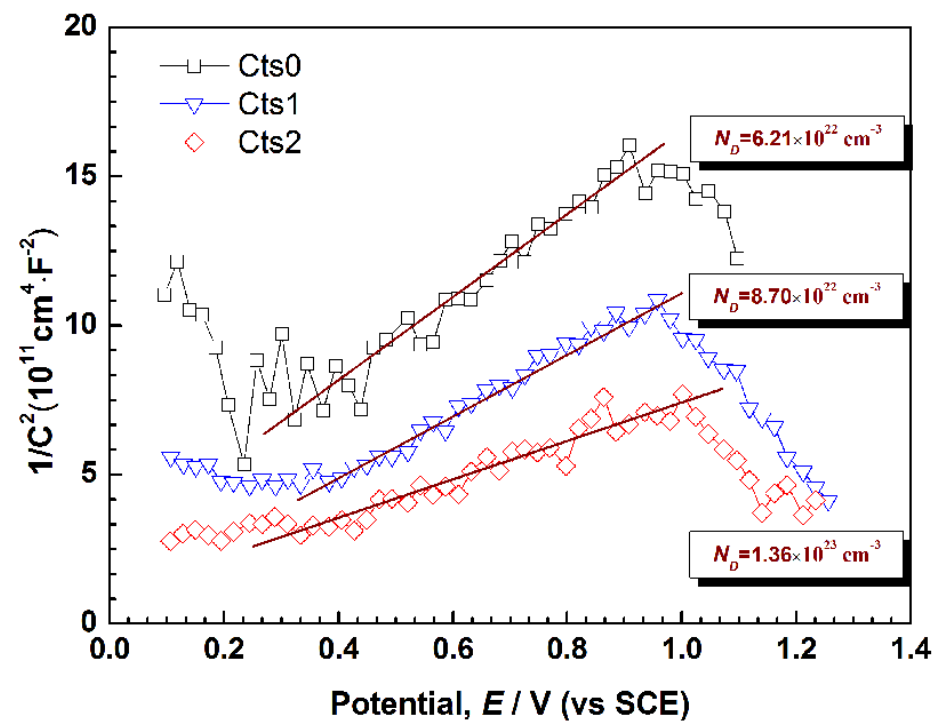

Wang et al./Fig.8 

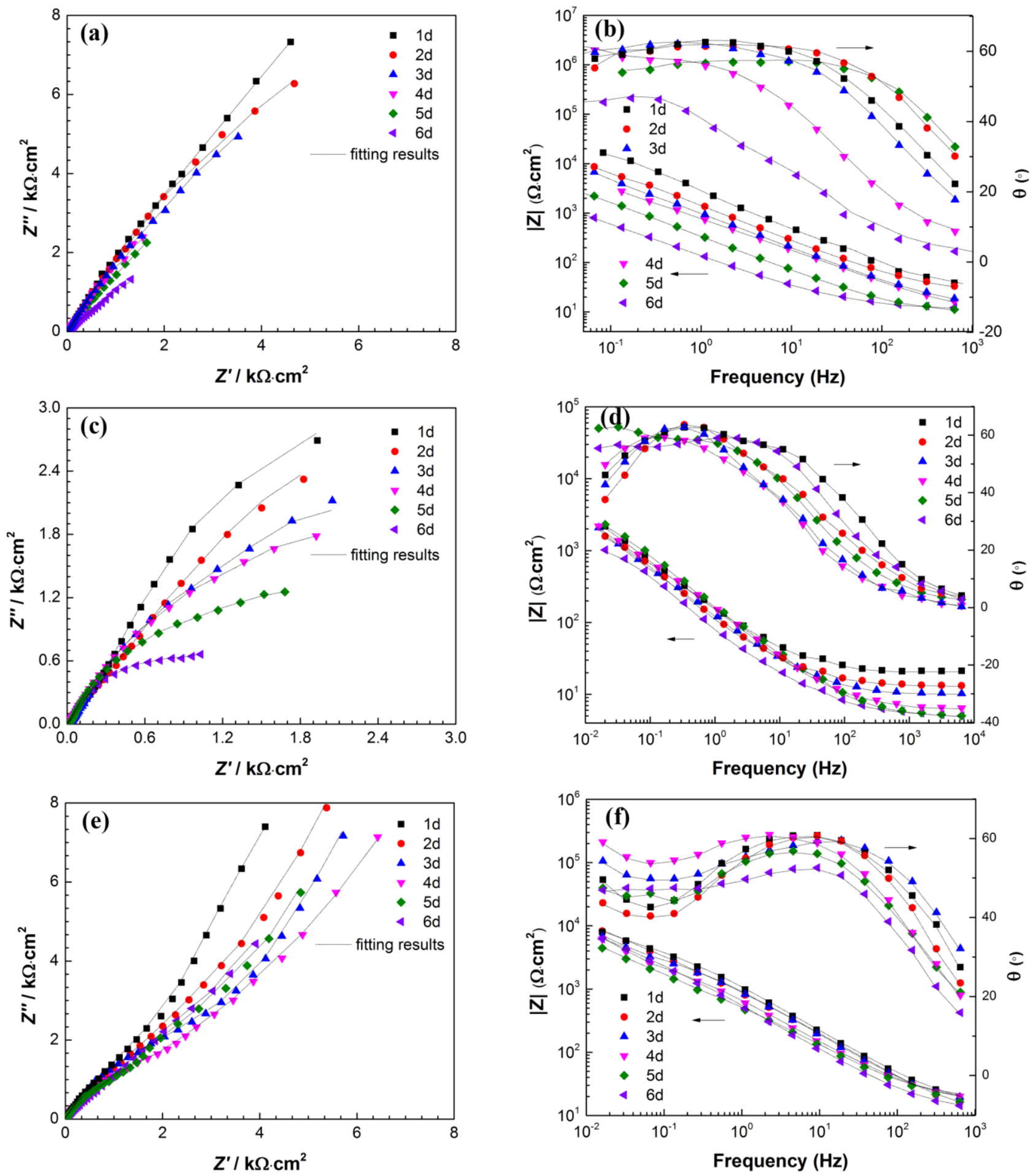

Wang et al./Fig.9 


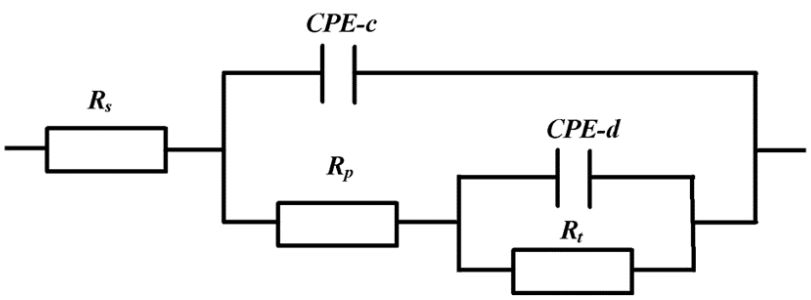

(a)

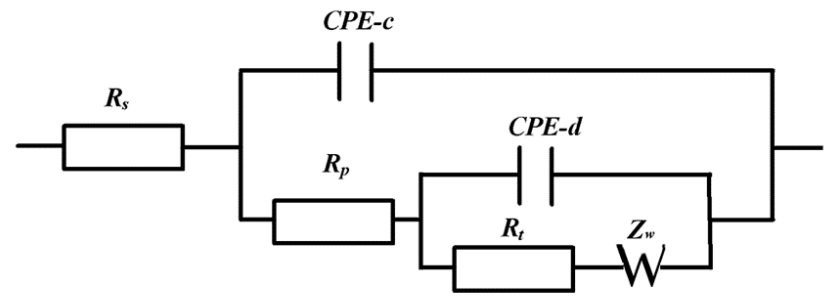

(b)

Wang et al./Fig.10 

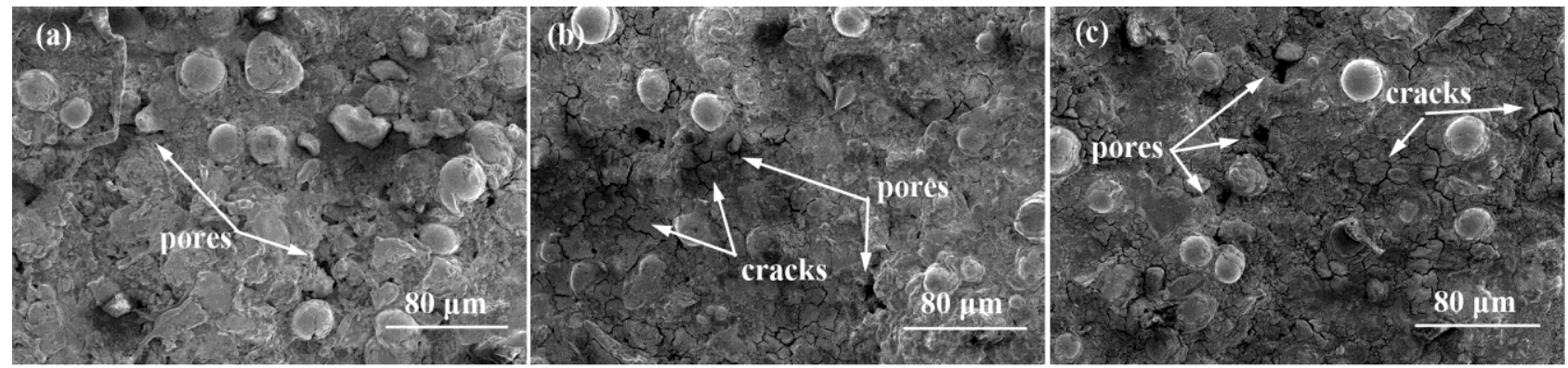

Wang et al./Fig. 11 


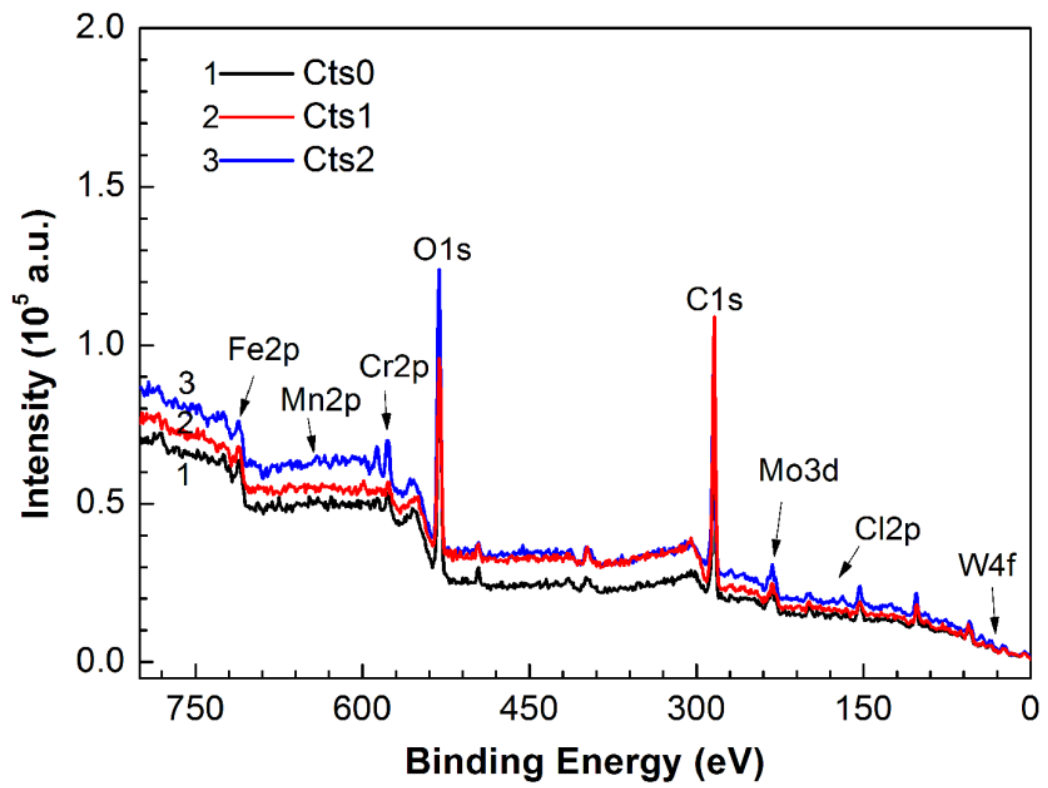

Wang et al./Fig.12 

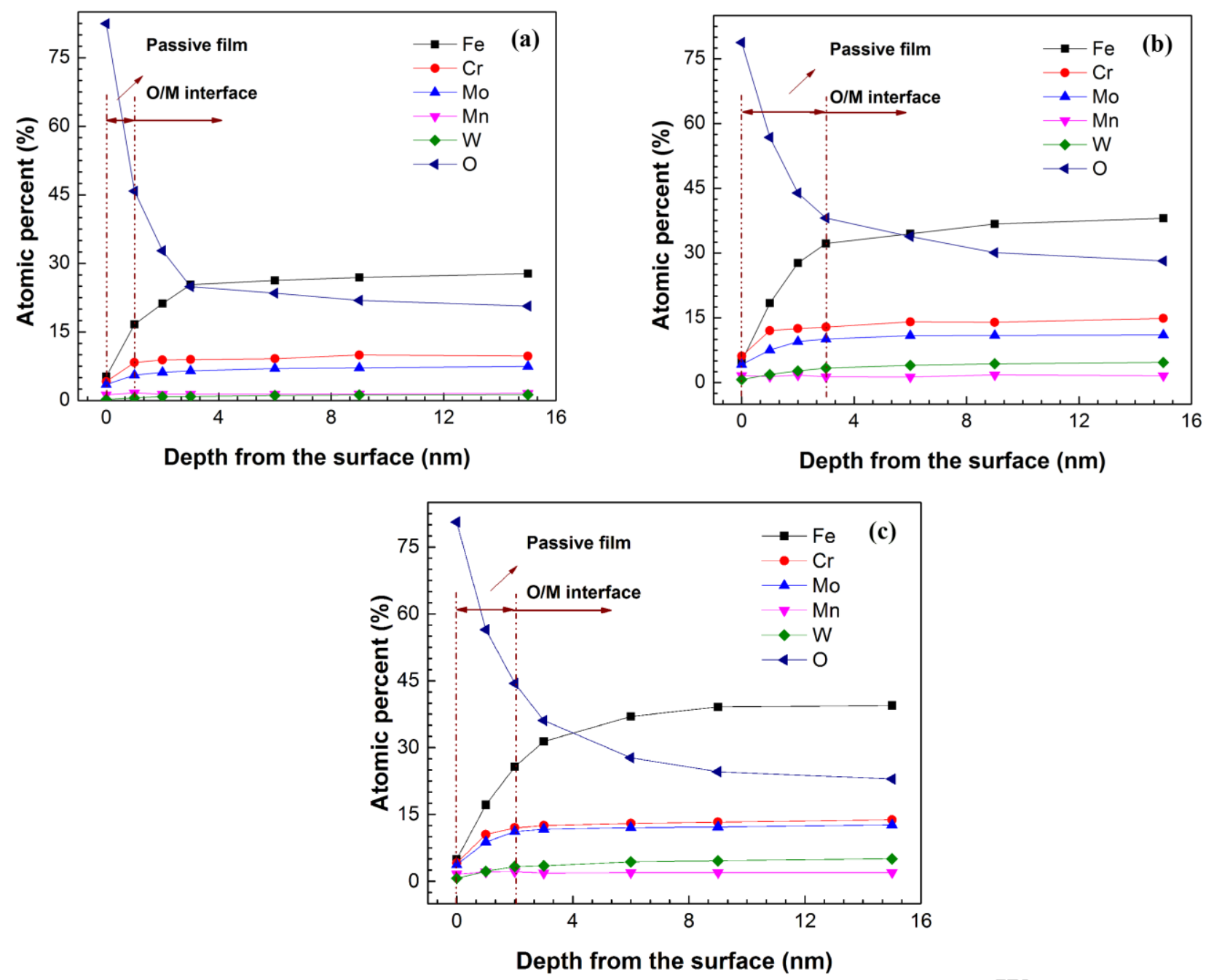

Wang et al./Fig.13 

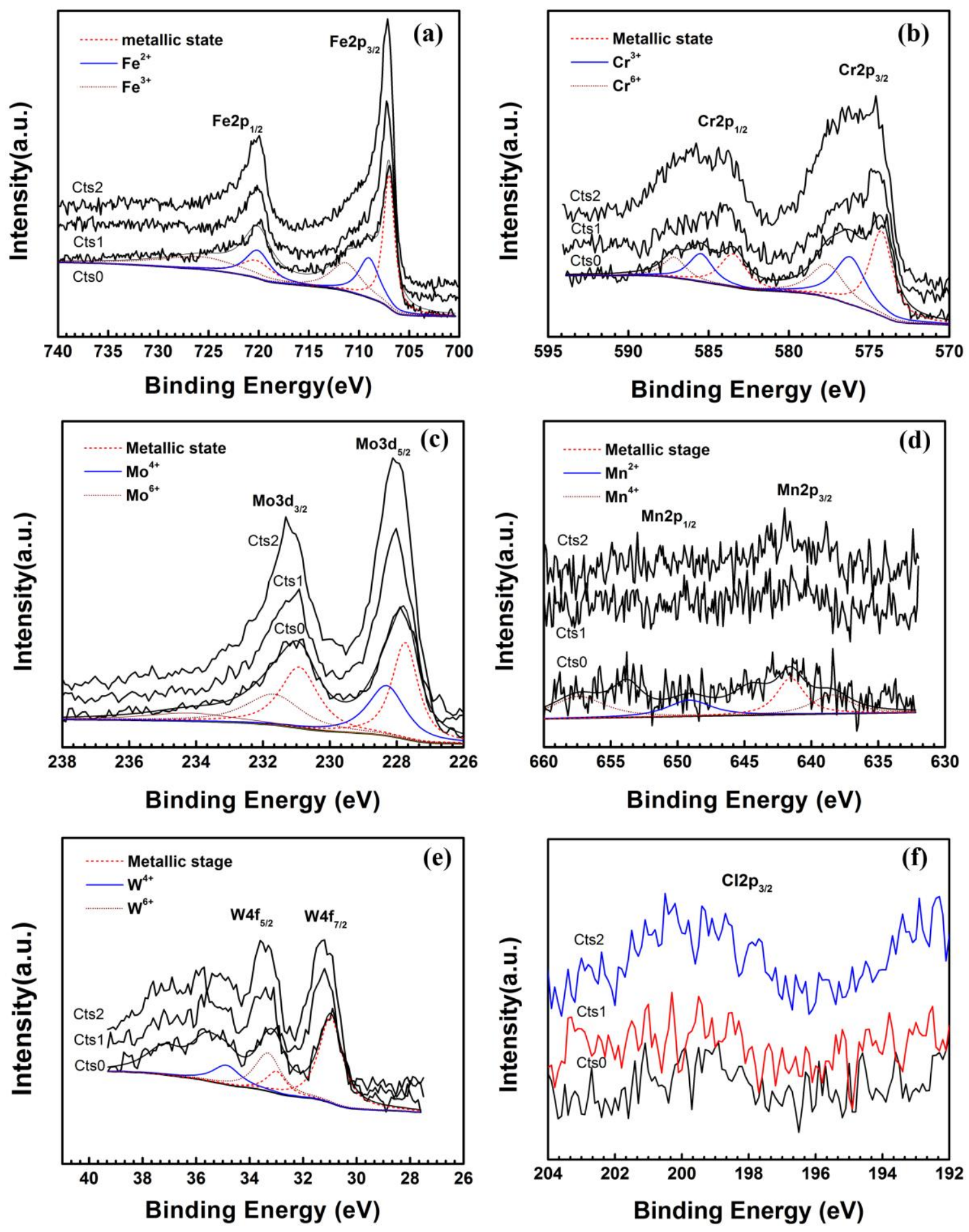

Wang et al./Fig.14 

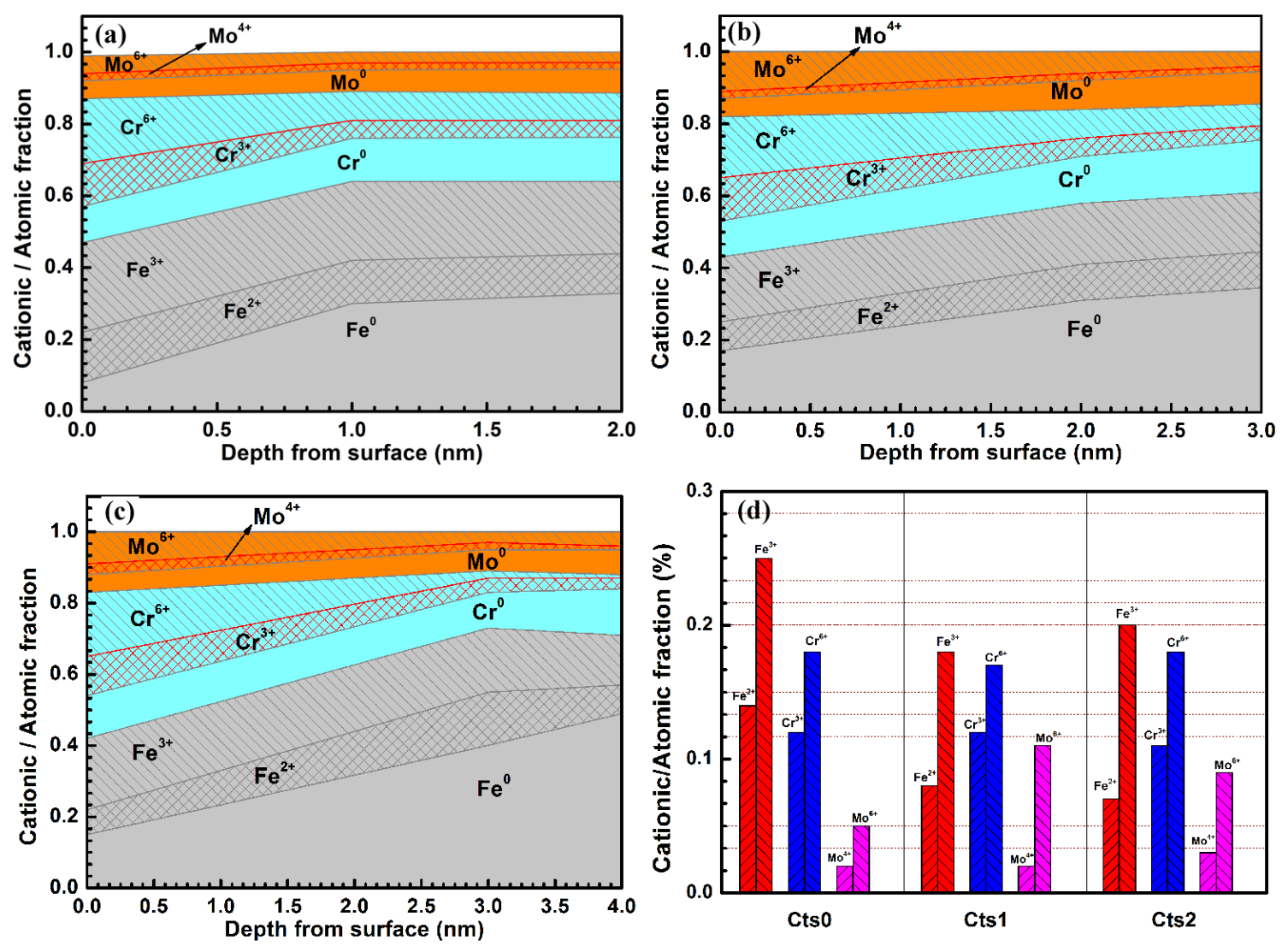

Wang et al./Fig. 15 